Wirtschaftswissenschaftliche

Fakultät

July 2015

\title{
Voluntary Corporate Climate Initiatives and Regulatory Loom: Batten Down the Hatches
}

Universität Basel

WWZ

Peter Merian-Weg 6

4052 Basel, Switzerland

wwz.unibas.ch

\section{Corresponding Author:}

Dr. Dragan Ilic

Tel +41612673357

dragan.ilic@unibas.ch

wwz.unibas.ch/ilic 


\title{
Voluntary Corporate Climate Initiatives and Regulatory Loom: Batten Down the Hatches
}

\author{
Dragan Ilić * and Janick Christian Mollet ${ }^{\text {s }}$ \\ * University of Basel \\ ${ }^{\circledR}$ ETH Zurich
}

July 13, 2015

\begin{abstract}
The rationale of voluntary corporate initiatives is often explained with preparedness for future regulation. We test this hypothesis for the Chicago Climate Exchange (CCX) and the Climate Leaders (CL), two popular voluntary US environmental programs to curb carbon emission that were operating during a decisive regulatory event. In 2009 the Waxman-Markey Bill surprisingly passed the House of Representatives and brought the US economy on the brink of a nationwide $\mathrm{CO}_{2}$ emission trading system. In an event study we assess how the stock market adjusted prices when the likelihood of $\mathrm{CO}_{2}$ regulation suddenly increased. Our results suggest that only membership in the CCX was considered beneficial, an initiative whose design happened to dovetail with the bill. Earlier membership announcement effects paint a complementary picture. But membership alone cannot account for the entire price adjustments. Our results reveal that a substantial part of the market reaction consisted of industry-wide effects.
\end{abstract}

JEL-Classifications: G38, Q53, Q54, Q58

Keywords: Voluntary markets, permit markets, climate change, greenhouse gas emissions, $\mathrm{CO}_{2}$, corporate social responsibility, shareholder wealth

* Author addresses: Dragan Ilic (corresponding author), University of Basel, Faculty of Business and Economics, Peter Merian-Weg 6, CH-4052 Basel, Switzerland, e-mail: dragan.ilic@unibas.ch; Janick Mollet, Center of Economic Research, ETH Zurich, e-mail: janick.mollet@gmail.com 


\section{Introduction}

The latest assessment report of the Intergovernmental Panel on Climate Change once again stresses the critical impact of $\mathrm{CO}_{2}$ emissions on the environment. Yet it does not seem likely that an agreement on a global framework to tackle climate change is achieved anytime soon. Notably the United States, one of the leading nations in greenhouse gas emissions, lacks federal legislation that addresses carbon emissions on firm level $]^{1}$ This was suddenly bound to change on 26 June 2009, when the US House of Representatives narrowly passed H.R. 2454, the "American Clean Energy and Security Act of 2009". Dubbed the Waxman-Markey Bill, this act aimed to cap $\mathrm{CO}_{2}$ emissions in the US with an emission trading system. The passage of this bill caught the public off guard. Even though the bill was gradually defeated later on, its success in the House of Representatives unexpectedly and substantially increased the likelihood of federal carbon legislation in the US.

Some firms seemed better prepared in light of this abrupt shift in looming legislation. Binding voluntary environmental initiatives credibly signal commitment and can provide a learning environment to improve the corporate footprint. In this paper we ask whether being a member in fitting initiatives pays off in risky times. To this end, we conduct an event study to compare the implications of corporate membership in two major $\mathrm{CO}_{2}$ abating programs that were operating during the passage of the Waxman-Markey Bill, the Chicago Climate Exchange (CCX) and the Climate Leaders (CL). More precisely, we analyze whether membership in the CCX and CL initiatives was rewarded by the financial markets in view of the unanticipated rise in likelihood of federal legislation. If this is the case, one motivation for firms to join such programs could indeed be preparation for regulation. In keeping with this argument, Bruce Braine, vice president of strategic policy analysis for American Electric Power described the motivation to participate in the CCX as follows: "Many of us were doing this not only to make voluntary commitments, but as a way that we could get prepared for a mandatory future. [...] We were learning the ropes, learning about trading and trying to become more proficient in reducing our carbon footprint over time." (National Geographic News, 2010) On the other hand, a lacking market reaction upon the passing of the bill would not speak for an economic value of such memberships for pending regulation.

Our study exploits a unique opportunity to compare two different designs to tackle $\mathrm{CO}_{2}$ emissions. The $\mathrm{CL}$ initiative pursued a broad approach with

\footnotetext{
${ }^{1}$ There are regional efforts: California has recently introduced a cap-and-trade program. However, the large number of allocated pollution permits has lead to a price decay. Other initiatives encompass several states. The Regional Greenhouse Gas Initiative aims to reduce greenhouse gases in nine US states in the northeast and is limited to large fossil fuel power plants.
} 
support from the US government. The CCX program was more streamlined, relied on independent verification, and was based on a market mechanism. As it happens, a similar mechanism was foreseen in the bill. We show that the particular fit of the design bears importance the the prescribed economic value. Our comparison thus adds another determinant to the relationship between environmental and economic performance (for a survey, see Blanco et al., 2009).

In order to round up the picture, in a complementary event study we compare how differently, if at all, the earlier announcement to join these programs had been gaged by the stock market. The direction of a possible reaction is not readily obvious. On the one hand, a shift to an engagement in voluntary programs could be perceived as detrimental from an investor's point of view. This is the case if the marginal benefits of the engagement are lower than its marginal costs. Oberndorfer et al. (2013) for example show that the inclusion in a sustainability stock index is valued negatively by the stock market. On the other hand, investors might perceive voluntary carbon reduction programs as a fitting training ground to acquire technical knowledge and improve operational efficiency, an advantage that increases the marginal benefits of these programs. If so, stock market reactions could be favorable. For CL firms, this very question was previously answered in an event study by Fisher-Vanden and Thorburn (2011). In the seeming absence of regulatory pressure, newly declared CL firms were vigorously penalized in terms of falling stock prices. Our second event study complements this picture with CCX membership announcement effects.

There is existing research on CCX membership announcement reactions and reactions to the Waxman-Markey Bill, but there remain serious questions. Using a conventional difference-in-differences framework with monthly stock returns, Gans and Hintermann (2013) purport that, for both the membership announcements and the Waxman-Markey Bill, the stock market reacted favorably towards CCX firms. However, the effects for CL firms (in Fisher-Vanden and Thorburn) and for CCX firms (in Gans and Hintermann) are not directly comparable. For one, test statistics of shorthorizon event studies are better specified than those of long-horizon event studies. More importantly, the CCX sample was not screened for confounding factors. This is not just a minor technical quibble. It is not clear to what extent the estimated return effects for the CCX firms in Gans and Hintermann's study are actually attributable to the events in question.

This paper thus pieces together a puzzle by extending, rectifying, and refining the existing findings. We provide a comprehensive and nuanced picture of the perceived value of membership in voluntary corporate climate initiatives by means of conclusive event studies. Our analysis fills two gaps in the literature. First, we establish a direct comparision of two distinct initiatives. There already is reason to believe that the market had deemed the value of becoming a member in these two programs differently, so we 
might also observe disparate reactions when push came to shove with the Waxman-Markey Bill. We argue that an environmental program that is tailored to the specific threat of future regulation by a mandated cap-andtrade system is likely to be a more effective tool to mediate the effect of an according shock. To round up the comparison of the two initiatives, we juxtapose the prior market reactions towards the membership announcements. In our second contribution to the literature, we highlight the important role of industry-specific effects when assessing the impact of unexpected regulation. It turns out that industry-specific effects explain a substantial part of the observed market reaction for CCX firms and fully account for the reactions for CL firms during the Waxman-Markey Bill. This supports the notion that the passage of the bill had not been priced in by the market. But more importantly, this insight stresses that neglecting industry-wide effects bears the risk of misinterpreting selective data.

The results of our event studies are in accord with the conjecture that, by and large, membership in the CCX initiative was throughout considered more valuable than membership in the CL. Conservative estimates suggest that, on average, stock prices of CCX members experienced positive abnormal returns of 0.7 percent during the passage of the Waxman-Markey Bill. CL members, on the other hand, hardly provoked any abnormal returns. In our complementary event study we find no measurable market reaction for firms announcing membership to the CCX. Taken together, these results qualify and reconcile previous findings and paint a coherent picture of the perceived market value of the two initiatives.

The rest of the paper is structured as follows. The next section provides background information on the Waxman-Markey Bill, the two voluntary corporate climate initiatives, and the related literature. Section 3 lays out the event study methodology, followed by the description of our data in Section 4. The results of the two event studies are presented in Section 5, and the last section concludes.

\section{Background}

\subsection{Waxman-Markey}

H.R. 2454, the "American Clean Energy and Security Act of 2009" was a Bill to propose, among other things, the introduction of a cap-and-trade system. The bill, also known as the Waxman-Markey Bill, would regulate the emission of greenhouse gases in the United States, in particular $\mathrm{CO}_{2}$. The new law was to replace existing voluntary action with mandatory legislation. Over the next 40 years carbon emissions were to be increasingly capped up to $83 \%$ of 2005 levels. Allocated with $\mathrm{CO}_{2}$ allowances, regulated 
firms would be free to trade their pollution rights at market prices ${ }^{2}$

After months of negotiations, on Friday June 262009 at 7:17 p.m. the House of Representatives narrowly passed the bill by a vote of 219 to 212 . The media response proclaimed the legislation as historic for the United States and a victory for the Obama administration. The outcome had remained rather unlikely to the end and stirred up subsequent emotions, pointing towards a controversial and unexpected decision. Actual market data support the qualitative impression of the passing as a surprise (Meng, 2013) $3^{3}$ In Section 5 we identify industry-specific effects that lend additional support to the unexpected nature of the passage of the bill.

Although at that time it still remained to be seen whether the Senate would approve the bill as well, there was suddenly good reason to believe that firms were more likely to face substantial costs in terms of $\mathrm{CO}_{2}$ reduction efforts in the near future. In contrast, the eventual defeat of the bill did not exhibit any sudden change in expectations. There was gradually less support over the months following the passage in the House of Representatives, leading up to the eventual defeat in the Senate in July 2010. This only makes the passage of the bill (and not its defeat) a viable candidate for an event study.

\subsection{Chicago Climate Exchange and Climate Leaders}

Two major initiatives to curb greenhouse gas emissions in the US were operating during the passage of the Waxman-Markey Bill. Both initiatives had been launched in the early 2000s. The so-called Chicago Climate Exchange (CCX) was a trade platform for $\mathrm{CO}_{2}$ certificates. Its members agreed to a reduction goal and independent verification of their efforts. As such, the CCX could be considered some type of predecessor to the government-based emission trading system intended by the Waxman-Markey Bill. The second initiative was the Climate Leaders (CL) program, which was an industrygovernment partnership to help firms reduce emissions of six major greenhouse gases. Participating members pledged to a realistic reduction goal

\footnotetext{
${ }^{2}$ Although the cap-and-trade system constituted the most prominent element of the legislation, the contents of the bill extend beyond this market instrument. It was a comprehensive strategy to address climate change. As such, the bill included policies of "creating a combined energy efficiency and renewable electricity standard and requiring retail electricity suppliers to meet $20 \%$ of their demand through renewable electricity and electricity savings by 2020" and "setting a goal of, and requiring a strategic plan for, improving overall U.S. energy productivity by at least $2.5 \%$ per year by 2012 and maintaining that improvement rate through 2030". The bill was accessed on October 92012 on http://www.govtrack.us/congress/bills/111/hr2454

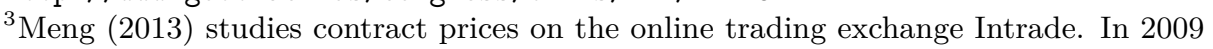
and 2010, a prediction market contract on the prospects of a U.S. cap-and-trade system was hosted on this exchange, essentially reflecting market expectations on the probability of this event. The time series of this contract's price indicates that the market swiftly adjusted expectations upon the passing of the bill.
} 
within a five to ten year time frame. Although these two initiatives pursued the same goal, their approaches differed in fundamental aspects. We present each initiative in turn.

In 2003, the Chicago Climate Exchange (CCX) started trading operations of the first cap-and-trade system in North America with 13 charter members that made voluntary but legally binding commitments to reduce six different types of greenhouse gas emissions $4^{4}$ The exchange was characterized by a market mechanism; a platform where prices were considered and allowances exchanged, and where strategic interaction took place. As part of its cap-and-trade scheme the CCX relied on a carbon offset program with its own standards for allowances and offset credits called "Carbon Financial Instrument Contracts". Established emission baselines and emission reports were verified independently. The CCX timeline can be divided into two distinct phases. From 2003 to 2006 members had to cut their emissions annually by $1 \%$ below their baseline average as defined from 1998 to 2001 . In the second phase from 2007 to 2010, existing members had to cut emissions annually by $0.5 \%$ while new members had to cut emissions by $1.5 \%$. In addition to the direct emitters (CCX members) there were associate members, offset providers, liquidity providers, and exchange participants. Over the course of its operation the exchange had had around 400 members with annual membership fees ranging from 1,000-60,000 USD, depending on firm size and membership type 5 In November 2010, the CCX announced that it would shut down the program, arguing that firms were no longer interested in trading emission credits in the absence of government legislation (Financial Times, 2010).

The Climate Leaders Greenhouse Gas Inventory Protocol is the second major voluntary initiative that operated during the passage of the WaxmanMarkey Bill. Formed in 2002, the Climate Leaders (CL) initiative was based on the Greenhouse Gas Protocol developed by the World Resources Institute and the World Business Council for Sustainable Development. The CL members did not restrict themselves to $\mathrm{CO}_{2}$ reductions but dedicated themselves to six main greenhouse gas emissions. These emissions were grouped into direct emissions (known as Scope 1), indirect emissions (known as Scope 2 ), and offered the reduction of optional emissions (known as Scope 3). In contrast to the CCX, the CL program was an industry-government partnership initiated by the US Environmental Protection Agency (EPA) that worked with companies to develop comprehensive climate change strategies. Upon becoming a partner, the EPA assisted each company in developing inventory and inventory management plans. Partners then set a corporatewide domestic or global five to ten year greenhouse gas reduction goal and

\footnotetext{
${ }^{4}$ CCX Fact Sheet, December 2011. https://www.theice.com/publicdocs/ccx/CCX_ Fact_Sheet.pdf, visited on January 142013

http://co2offsetresearch.org/policy/CCX.html, visited on December 202012
} 
reported annual inventory data to the EPA. In addition, partners were to document their progress towards the goal (Tonkonogy and Oliva, 2007).

But unlike the CCX, the CL did not rely on mandatory third party verification, rendering their environmental efforts less traceable. This difference can have serious consequences. In a field experiment, Telle (2013) finds evidence that firms under-report environmental violations in self-audits. To external parties, then, the CL design radiates less credibility in terms of commitment than the CCX design.

Four types of reduction goals were eligible for CL members: absolute, normalized, indexed, or carbon neutrality. Upon engagement, the EPA evaluated the proposed reduction goals from all partners, requiring a reduction compared to the projected GHG performance of the sector. Partners were also allowed to develop their own mitigation offset projects or purchase certified mandatory or voluntary GHG reductions, provided that the projects adhered to approved EPA methodologies. Contrary to the CCX, there were no explicit market mechanisms at work. Upon joining, it was not decisionmaking based on market prices that influenced the daily carbon business. Instead, according to the EPA, partners were sure to receive high level recognition via participation in meetings, public outreach, or press events (Tonkonogy and Oliva, 2007). Members also profited from the EPA's technical assistance. On September 15 2010, the EPA announced their decision to cease operation of the CL program in light of new political developments.

\subsection{Related Literature}

Traditional economic analysis assumes that firms already behave optimally, with pollution being an inevitable side product of production (Cropper and Oates, 1992). So at first glance, there is no rationale to voluntarily reduce pollution. Yet it turns out that one can explain such voluntary engagement in a number of ways. The literature has identified a variety of economic motives, some of which are based on some sort of imperfect markets (for an overview, see Khanna, 2002, Portney, 2008). These motives can be roughly divided into market motives and political motives (Fleckinger and Glachant 2011).

Political motives seem particularly interesting for our case. Lyon and Maxwell (2003, 2008) argue that by participating in voluntary environmental initiatives firms seek to preempt or shape future public policies. On this note, perhaps the most pertinent argument that rationalizes voluntary participation in our setting is preparation for some expected legislation. If there is reason to believe that with a non-negligible probability future environmental legislation will impose costly regulation upon firms, it might be reasonable to dampen the impact of such a future shock by adjusting corporate behavior today and thus prepare voluntarily. For a smooth path towards the expected extent of the regulation entails lower overall costs 
than a sudden adjustment. Unexpected changes in legislation such as the Waxman-Markey Bill provide a testing ground for this hypothesis. If the market correctly interprets the impact of suddenly looming legislation, we should observe immediate changes for the prices of markedly affected stocks.

There is a large body of evidence that supports the view that a sudden increase in the likelihood of future regulation is taken into account by the market. For instance, Bowen et al. (1983) and Hill and Schneeweis (1983) suggest that the nuclear incident at the Three Mile Island facility in 1979 altered the investors' perception of future regulation by resulting in a sudden drop in stock prices for electric utility firms, in particular for those who were invested in nuclear power. The chemical disaster in Bhopal in 1984 had a similar effect. Once the extent of the tragedy had become clear, the market seemingly anticipated tighter regulation for the entire chemical industry (Blacconiere and Patten, 1994). Price shocks can trigger market reactions as well. Bushnell et al. (2013) show that the 50\% drop in the EU $\mathrm{CO}_{2}$ allowance price in 2006 affected stock prices in carbon- and electricityintensive industries. Unexpected policy changes can work as shocks, too. The sudden proposal by President George Bush in 1989 to revise the Clean Air Act triggered a drop in stock prices of notoriously polluting coal firms (Freedman and Patten, 2004 , Kahn and Knittel, 2003). And very recently, the unexpected reaction of the German government to the Fukushima incident affected energy companies' shareholder wealth (Betzer et al., 2013).

By and large, this suggests that the market interprets new and strict regulation as impending threats. Yet some firms seem to fare better in harsh times. There is empirical evidence that voluntary engagement and subsequent verified disclosure is rewarded by the market because of their informational value when external shocks materialize. For example, more extensively disclosing firms were at an advantage after the chemical leak in Bhopal (Blacconiere and Patten, 1994). The same held true after the sudden legislation in the US in 1986 to handle contaminated sites (Blacconiere and Northcut, 1997). And firms that were part of the Carbon Disclosure Project experienced an increase in shareholder value when Russia unexpectedly ratified the Kyoto Protocol in 2004 (Kim and Lyon, 2011). All of these events qualify as external shocks that increased the likelihood for environmental regulation.

The Waxman-Markey Bill has all the hallmarks of such a regulatory shock. The market suddenly needed to price in new information in light of pending future regulation, a regulation that would affect entire industries. Against this background, the two voluntary initiatives in question, the CCX and the CL program, were informative of the members' preparedness for the upcoming regulation. If these initiatives were deemed advantageous by the market, the members of the programs should have fared relatively better in terms of stock price adjustments.

There are two studies addressing the economic value of membership in 
voluntary environmental initiatives that are directly related to our paper. The event study by Fisher-Vanden and Thorburn (2011) investigates the announcement effects for firms joining the CL program. The study finds striking negative abnormal returns for announcing membership. On the day of the announcement, stock market returns of the new CL firms performed one percent worse than expected. Announcing a binding $\mathrm{CO}_{2}$ target incurred an additional penalty of 1.1 percent.

The second paper that relates to our work is the study by Gans and Hintermann (2013). Gans and Hintermann investigate stock returns of CCX members on a monthly basis. Contrary to the CL firms in Fisher-Vanden and Thorburn, they find significant positive abnormal returns for announcing membership to the CCX. Gans and Hintermann, too, consider the passing of the Waxman-Markey Bill as a shock. They assess the financial impact of the bill on CCX firms and find a positive market reaction from one month to the next. However, that study design contains serious methodological drawbacks. While the results of their difference-in-differences framework are helpful, such a methodology is rather unusual when using market data to estimate the financial impact of unexpected events. The large time window associated with monthly returns makes it difficult to isolate the effect of membership. Brown and Warner (1980), for instance, document the problem of using monthly data by illustrating that the degree of misspecification in event tests can be severe. This issue is exacerbated by the fact that the reported impact of the Waxman-Markey Bill was not screened for confounding events at the firm level during the time of the event. In a well-known replication study, McWilliams and Siegel (1997) highlight the importance of accounting for such confoundings.

We address these issues and reconcile the existing evidence. Our paper follows the precise event study methodology applied in Fisher-Vanden and Thorburn and provides conclusive and comprehensive results of the impacts of membership announcement for CCX firms on the one hand and the Waxman-Markey Bill for both CCX and CL firms on the other hand. Our results benefit from higher explanatory power and allow for a direct comparison of the two initiatives for two kariotic moments.

\section{Methodology}

This section constructs an event study and uses financial market information (stock prices) to deduce the effects of our events on firm value 6 This approach has the advantage that it isolates the causal chain quite effectively. An event has a direct impact on the stock price, similar to a treatment ef-

\footnotetext{
${ }^{6}$ Event studies have become an indispensable tool in econometrics. MacKinlay (1997) gives a comprehensive overview of the history, theory, and application of event studies in economics.
} 
fect. The statistical inference in an event study relies on three assumptions (McWilliams and Siegel, 1997): market efficiency, a lack of confounding effects during the event window, and under-/overestimation or no anticipation of the event. Indeed, if the event in question had been anticipated, investors would have already had priced in its predicted impact on firm value. Although the passage of the Waxman-Markey Bill was not out of question, Section 2.1 presented evidence that it was largely unexpected and provided the market with new information.

The measurement of the value impact of an event is carried out by calculating the so-called abnormal return. The abnormal return (AR) is the observed return minus the normal return during a specified event window, where the normal return is the return that one would expect to occur if the event had not taken place. The abnormal return $A R_{i \tau}$ is given by equation 1 . where $E\left(R_{i \tau} \mid X_{\tau}\right)$ is the expected return $R_{i \tau}$ given $X_{\tau}$.

$$
A R_{i \tau}=R_{i \tau}-E\left(R_{i \tau} \mid X_{\tau}\right)
$$

In financial economics, the normal return is often modeled via the market model, which relates the return of interest $R_{i \tau}$ to the market return $R_{m \tau}$. In a nutshell, the market model isolates the fraction of the return that is associated with the market return, rendering the return of interest more informative. The parameter estimates of the market model are calculated in an Ordinary Least Squares framework on the basis of a preceding estimation window. In addition to the market return, our specification additionally employs Fama-French's "small minus big" (SMB) and "high minus low" (HML) factors on a daily basis as explanatory variables (Fama and French, 1992 , 1993). Kolari and Pynnonen (2010) illustrate that the addition of these factors achieves the highest reduction of residual cross-correlation. Taken together, we estimate the following model specification:

$$
R_{i \tau}=\alpha_{i}+\beta_{i 1} \cdot R_{m \tau}+\beta_{i 1} \cdot S M B_{\tau}+\beta_{i 2} \cdot H M L_{\tau}+\epsilon_{i \tau}
$$

$S M B$ in equation 2 denotes the daily difference of a portfolio of small and big firms and $H M L$ indicates the daily difference of a portfolio of low and high book-to-market value firms $77 \epsilon_{i \tau}$ is the remaining error term after estimating $E\left(R_{i \tau} \mid X_{\tau}\right)$ and follows from $\epsilon_{i \tau}=A R_{i \tau}=R_{i \tau}-E\left(R_{i \tau} \mid X_{\tau}\right)$ via equation 1 . We call the model in equation 2 the 3 -factor model or the baseline specification. We extend this specification by adding industry return factors $E S r e t_{j \tau}$ and $B S_{r e t} t_{\gamma \tau}$ in equation 3 and 4 respectively, to control for industry effects:

\footnotetext{
${ }^{7}$ Downloaded from Kenneth French's website: http://mba.tuck.dartmouth.edu/ pages/faculty/ken.french/data_library.html
} 


$$
\begin{aligned}
& R_{i \tau}=\alpha_{i}+\beta_{1 i} \cdot R_{m \tau}+\beta_{2 i} \cdot S M B_{\tau}+\beta_{3 i} \cdot H M L_{\tau}+\beta_{4 i} \cdot \text { ESret }_{j \tau}+\epsilon_{i \tau} \\
& R_{i \tau}=\alpha_{i}+\beta_{1 i} \cdot R_{m \tau}+\beta_{2 i} \cdot S M B_{\tau}+\beta_{3 i} \cdot H M L_{\tau}+\beta_{4 i} \cdot \text { BSret }_{\gamma \tau}+\epsilon_{i \tau}
\end{aligned}
$$

In ESret $_{j \tau}, j$ denotes one of 10 economic sectors and in BUSret ${ }_{\gamma \tau}$, $\gamma$ denotes one of 25 business sectors according to the Thomson Reuters Business Classification.

The event takes place after the estimation window and is usually placed inside the so-called event window, during which the observed returns are compared to the expected ones. Because some events cannot be unambiguously dated, for example due to gradual information leakage or potential insider information, researchers often include several days around the official date $\tau=0$ into the event window. However, this comes at a cost. A longer time series of $A R_{i \tau}$ diminishes the power of the test statistics and tends to increase the number of confounding events. Not to mention that a long event window is even more difficult to reconcile with the notion of market efficiency. Contrary to long-horizon event studies, the test statistics of short-horizon event studies are generally less sensitive to the benchmark model of normal returns and issues of both cross-sectional and time-series dependence of abnormal returns (Kothari and Warner, 2007).

In our data, $R_{i \tau}$ is the total return index based on closing prices. The closing price of day $\tau-1$ is the opening price of day $\tau$. In the event window notation $\left[T_{2}, T_{3}\right], T_{2}$ referres to the opening price on day $\tau=0$ and $T_{3}$ to the closing price on day $\tau$. The event window $[1,1]$ therefore captures the return on the day after the event day $\tau=0$. We are interested in two events, the Waxman-Markey Bill and membership announcements. In our first event study, we define the Waxman-Markey event day, Friday 26 June 2009, as $\tau=0$ and set the estimation window to 60 trading days from $T_{0}=-59$ to $T_{1}=0$. For the Waxman-Markey event, the event day $\tau=0$, a Friday, is included in this estimation window, for two reasons: First, the vote took place at $7 \mathrm{pm}$ and therefore after the closing of the stock exchanges. Second, the issue of potential information leakage can be excluded because the outcome of the vote was extremely close and the public outcry thereafter was substantial. Speaking in trading days, our event window $[1,1]$ is set rather narrowly after the event and captures the abnormal returns on day one after the event, Monday June 29, with $T_{2}=1$ and $T_{3}=1$. Note, however, that the weekend precedes the event window, which should provide enough time for the news to spread. We also employ a second, longer window that estimates the returns over $[1,2]$.

For the second event in question, the CCX membership announcements, we extend the narrow event windows to take into account potential prior information leakage. To allow for a direct comparison for the CL membership announcement effects in Fisher-Vanden and Thorburn (2011) we 
choose their event windows $[0,1],[-1,1]$, and $[-2,2]$. Setting the estimation window to 60 days thus sets a span from $T_{0}=-62$ to $T_{1}=-3$. In turn, the cross-sectional abnormal returns $A R_{i \tau}$ in the event window are cumulated from $T_{2}$ until $T_{3}$. This yields the cumulative abnormal returns $C A R_{i\left[T_{2}, T_{3}\right]}=\sum_{\tau=T_{2}}^{T_{3}} A R_{i \tau}$. Average CARs are obtained by averaging the CARs across the observations: $A C A R_{\left[T_{2}, T_{3}\right]}=\frac{1}{n} \sum_{i=1}^{n} C A R_{i\left[T_{2}, T_{3}\right]}$.

The raw returns are useful for economic interpretations. Standardized returns, however, have been proven to exhibit better statistical properties (Patell, 1976). The scaled abnormal returns are equal to $S A R_{i \tau}=\frac{A R_{i \tau}}{S\left(A R_{i}\right)}$, where $S\left(A R_{i}\right)=\sqrt{\sigma_{\epsilon_{i}}^{2} *\left[1+x_{t}^{\prime}\left(X^{\prime} X\right)^{-1} x_{t}\right]}$ denotes the sampling error correction. The $S A R$ s can be cumulated over time as well: $C S A R_{i\left[T_{2}, T_{3}\right]}=$ $\sum_{\tau=T_{2}}^{T_{3}} S A R_{i \tau}$. The cross sectional means of these cumulative standardized abnormal returns are equal to $A S C A R_{\left[T_{2}, T_{3}\right]}=\frac{1}{n} \sum_{i=1}^{n} C S A R_{i\left[T_{2}, T_{3}\right]}$.

In comparison to a conventional t-test or Patell's test, the test proposed by Boehmer et al. (1991) given in equation 5 is robust against event induced variance inflation. Harrington and Shrider (2013) show that the presence of heterogeneous effects induces event variance. Robust tests against crosssectional variation in the true abnormal return should therefore be preferred.

$$
t_{B M P}=\frac{A C S A R \cdot \sqrt{n}}{\frac{1}{n-1} \sum_{i=1}^{n}\left(C S A R_{i}-A C S A R\right)^{2}}
$$

A particular issue for the Waxman-Markey event is clustering. In contrast to the membership announcements, the bill affected the firms simultaneously at the same point in time. One might thus question the assumption that $\epsilon_{i \tau}$ is independent and identically distributed. MacKinlay (1997) suggests that clustering can be accommodated in two ways. Either by a portfolio approach which allows for cross correlation of the abnormal returns, or by analyzing the abnormal returns without aggregation, e.g. by including a dummy for the event day. The latter approach has two drawbacks. Such a test will generally suffer from poor finite sample properties and has little power against reasonable alternatives. As a remedy, Kolari and Pynnonen (2010) propose a modification of the test statistic developed by Boehmer et al. (1991) that is not affected by clustering. Kolari and Pynnonen's statistic increases the cross sectional variance used by Boehmer et al. (1991) by adjusting for the average covariance of the error terms $\bar{\rho}$ during the estimation window:

$$
t_{K P}=t_{B M P} \sqrt{\frac{1-\bar{\rho}}{1+(n-1) \bar{\rho}}}
$$

We consider the Kolari and Pynnonen (2010) test statistic to be the most 
appropriate for our samples. In addition, we make use of the non-parametric generalized rank test proposed in Kolari et al. (2010) to check the robustness of our parametric tests. We choose the generalized rank test because it has better properties for testing CARs than the conventional rank test and is equally well suited for testing single day abnormal returns.

\section{Data}

This section describes our CCX and CL samples. Gans and Hintermann have kindly provided us with their CCX database and data on their selection process.8 Their final sample for the Waxman-Markey event consists of 32 firms. We start with the same CCX database consisting of 109 members. Of these, 20 are government-affiliated and are cities, states, or universities. From the remaining 89 observations, we find listings for 57 firms in the US. From these listings we drop seven firms with discontinuous price indices, a sure sign of illiquid securities. From the remaining 53 firms, seven are American Depositary Receipts and three are not major listings or have their book values not denominated in USD. This leaves us with 40 identified CCX member firms for the Waxman-Markey event.

For a direct comparison to the CCX program we compile a database of CL firms. Recall that Fisher-Vanden and Thorburn only identify the announcement effect of firms joining CL. We extend their analysis and identify the effect of the Waxman-Markey Bill on then operating CL members. Our database starts with a CL member list retrieved from the US Environmental Protection Agency as of 8 May 2009.9 Of the 264 members at that time, we focus on the 19 achiever and 87 setter firms. The remaining 158 so-called developer firms are by definition at a very early stage of their membership. That status is hardly an advantage in light of the Waxman-Markey Bill. Indeed, the majority of the developer firms later on opted out of the program, questioning their motivation and commitment in the first place. For that reason, we exclude developer firms from our CL database ${ }^{10}$ Although we lack detailed membership status for the day of the passage of the WaxmanMarkey Bill, Table A1 in the appendix illustrates the development of the CL program over time. Of the 106 Climate Leaders with setter and achiever status, we identify 65 as being listed on a US stock market. Among these stocks, there are five illiquid equity return indices and three ADR listings. This yields an identified sample of 57 CL firms for the Waxman-Markey

\footnotetext{
${ }^{8}$ Their CCX sample is from 2010, but we found a document form February 2009 that lists the same CCX members: http://www.epa.gov/agstar/documents/workshop09/ mccomb.pdf, visited on December 102012.

${ }^{5}$ Obtained through www.archive.org on November 62012 via web.archive.org/web/ 20090508120744/http://epa.gov/climateleaders/partners/index.html

${ }^{10}$ urlhttp://www.epa.gov/climateleadership/documents/partners_letter_15sep2010.pdf, visited on December 92012
} 
event.

The first row of Table A2 lists the identified firms for both programs. For the Waxman-Markey event we conducted a thorough analysis of confounding events from 26 June 2009 (Friday) through 30 June 2009 (Tuesday) for both the CCX and the CL sample. For each firm in our two samples, we searched LexisNexis for unexpected announcements that were published in major US news outlets and which were likely to affect market value during the event window. The second row in Table A2 lists the number of confounding events for each program. For the $57 \mathrm{CL}$ firms, we identify 16 confounding events, leaving us with a final CL sample of 41 firms. For the 40 firms in the CCX sample we identify confounding events for nine firms, leaving us with a final CCX sample of 31 firms. An overview of our final samples for the Waxman-Markey event is given in Tables A3 and A4. We classify three samples: A pure CCX sample, a pure CL sample, and a pooled sample of CCX and CL firms. Table A3 lists our final CCX sample and indicates charter member status where applicable. Table A4 lists the final CL sample with the according membership status and whether the respective firms were charter partners.

In addition to the Waxman-Markey event we are interested in membership announcement effects. Fisher-Vanden and Thorburn have done this analysis for CL firms, so we restrict our attention to CCX member firms. To determine this sample we start with the same CCX database and apply the same filters as mentioned above. For the identified firms we search both Google and LexisNexis for membership announcement dates, resulting in the sample of 26 firms shown in Table A2. In contrast to the Waxman-Markey event here we cumulate abnormal returns for longer event windows due to potential information leakage. We search for confounding events up to two days before and two days after each membership announcement. We find six confounding events and end up with a sample of 20 CCX firms for the membership announcement event.

\section{Results}

This section presents the event study results for our two incidents. First, we investigate the market reaction to the Waxman-Markey Bill to our three samples, CCX, CL, and CCX plus CL. Second, we take a look at the market reaction to membership announcements for CCX firms alone, offering a direct comparison to the same reaction towards CL firms observed in FisherVanden and Thorburn (2011).

\subsection{Event Returns: Waxman-Markey Bill}

Table 1 presents descriptive statistics for the three samples. The pooled sample comprises 61 firms. On their own, the CCX sample consists of 31 firms 
Table 1: Descriptive Statistics

\begin{tabular}{lccc}
\hline & CL \& CCX & CCX & CL \\
\hline Number of firms & 60 & 31 & 41 \\
& & & \\
Market value (MV, billion USD) & & & \\
Mean MV & 18.1 & 17.7 & 24.1 \\
Median MV & 6.7 & 4.8 & 11.1 \\
& & & \\
Total sales (billion USD) & & & \\
Mean sales & 20.8 & 23.2 & 23.1 \\
Median sales & 10.3 & 9.3 & 14.4 \\
& & & \\
Market-to-book equity (MEBE) & & & \\
Mean MEBE & 1.9 & 2.1 & 2.0 \\
Median MEBE & 2.0 & 1.3 & 2.3 \\
& & & \\
Fraction of sample firms in TRBC ${ }^{*}$ sector: & & & \\
Basic Materials & 0.18 & 0.32 & 0.07 \\
Consumer Cyclicals & 0.15 & 0.06 & 0.20 \\
Consumer Non-Cyclicals & 0.05 & 0.00 & 0.07 \\
Financials & 0.02 & 0.03 & 0.02 \\
Healthcare & 0.05 & 0.03 & 0.07 \\
Industrials & 0.15 & 0.13 & 0.17 \\
Technology & 0.22 & 0.13 & 0.29 \\
Utilities & 0.18 & 0.29 & 0.10 \\
\hline
\end{tabular}

*TRBC: Thomson Reuters Business Classification.

The market value (MV) of equity is calculated seven trading days before June 292009.

The mnemonic of sales is WC01001 and of book equity WC03501 
and the CL sample 41 contains firms, meaning that six firms are members in both programs. The distribution of the market capitalization is positively skewed for the CCX and the CL samples, with CL members being substantially bigger. The two samples differ in the distribution of their sale volumes as well. Although CL firms have, on average, the same turnover as CCX firms, their median is higher. A similar skew is visible in market-to-book numbers. While the average of market-to-book equity is the same in both samples, the medians indicate a proclivity for value firms in the CCX sample and for growth firms in the CL sample. The two samples also differ in their industry exposures. Two economic sectors as classified by the Thomson Reuters Industry Classification are absent from our samples: Telecommunications and Energy. The other economic sectors are not equally distributed, neither across the CL nor the CCX sample. For example, the CCX sample harbors a larger fraction of basic materials and utilities, whereas the CL sample shows a tilt towards technology firms. We account for these differences in our extended model specifications.

We first estimate abnormal returns for all three samples using our baseline specification. To allow for value-relevant information to distribute and sink in, we conduct analyses for two event windows after the passage of the bill. Based on the baseline market model given by equation 2 we calculate the cumulated abnormal returns CAR $[1,1]$ for Monday (29 June) only and CAR $[1,2]$, which includes the following Tuesday.

Table 2 presents the abnormal returns and their derivatives according to our baseline specification. The results for the event windows $[1,1]$ and $[1,2]$ are depicted in panels $\mathrm{A}$ and $\mathrm{B}$, respectively. Across all samples, the average cumulated abnormal returns (ACAR) for the short event window are close to $0.5 \%$. Their standardized counterparts (CSAR) are substantially lower. Among the three samples, the CCX firms exhibit the highest standardized returns. The two-sided BMP test statistic by Boehmer et al. (1991) is highly significant across the board. The null hypothesis of normal returns is rejected at the $0.1 \%$ significance level for the CCX firms and at a slighty higher level for the CL firms. As expected, the more conservative KP p-values according to Kolari and Pynnonen (2010) are higher (roughly $3 \%$ for the CCX firms and $7.6 \%$ for CL firms). Finally, the nonparametric generalized rank test also rejects the null hypothesis of normal returns for the short event window.

The cumulated abnormal returns over two days in panel B indicate that the ACAR of the CCX sample increased to over $0.7 \%$ whereas the ACAR of the CL sample declined to $0.35 \%$. This suggests that the market incorporated additional price information on the second day after the event. The BMP statistic remains significant across the samples for this longer event window; for the CCX firms once again at the $0.1 \%$ level and less significantly for the CL firms at the $10 \%$ level. The KP p-values, however, only remain significant for the CCX and the pooled sample. Put differently, a 
conservative estimation suggests that the CL firms do not seem to exhibit abnormal returns when cumulated over two days. Again, the generalized rank test dovetails with the KP test.

Taken together, these results are consistent with the idea that financial markets believed that firms engaging in voluntary measures of carbon emission reduction get a head start in preparing for imminent federal carbon emission legislation. But not our two programs did not encounter equal praise. Based on the results of the baseline market model, membership in the CCX is considered more beneficial in light of the Waxman-Markey Bill compared to membership in the CL program.

All the same, the heterogeneous sector distributions for the CCX and CL firms give pause. The CL and CCX firms are not readily comparable in terms of sector distribution. But the empirical evidence listed in Section 2 suggests that some sectors exhibit a higher vulnerability to regulatory shocks. The results in Table 2 are based on the baseline 3 -factor model, which benchmarks a firm's returns against the market return and the two Fama-French risk factors SMB and HML. As such, the results are prone to industry-specific effects. These specific effects could stem from two potential sources. For one, firms from industries that are generally positively affected by a mandatory emission cap-and-trade system could be more likely to opt into voluntary emission reduction programs. Second, the Waxman-Markey event took place in the midst of an economic recession, a recession which did not affect all industries alike. In order to isolate the CCX and CL membership effect from such overarching effects, we proceed by controlling for industry-specific confoundings and extend the baseline market model with both economic and, to reach a deeper level, business sector returns.

In a first step, we incorporate industry return factors from 10 economic sectors. For each security $i$ in sector $j$ we add to the baseline market model the economic sector return $j$ as defined in equation 3. Table A5 summarizes the results of this second specification. It turns out that economic sector returns explain a substantial part of the observed positive effects from the baseline specification. By any measure of statistical significance and for both event windows, the abnormal returns of the pooled sample are no longer different from zero. The two pure samples present a more nuanced picture. In the previous analysis, the CL sample only showed significant returns for the short event window. This significance now disappears altogether with the inclusion of industry-specific effects. The CCX sample, on the other hand, keeps showing (slightly less) significant abnormal returns, in particular for the longer event window. In this window, the CARs and CSARs for the CCX firms are somewhat reduced. The second model specification thus indicates that positive sectoral effects have been at work, much more so for the CL than for the CCX sample. This also explains why the perpetually observable abnormal returns for the CCX sample dilutes in the pooled sample.

To further check the robustness of the economic sector results, we ex- 
Table 2: 3-Factor Model

\section{CL\&CCX CCX CL}

\section{Panel A: Event Window $[1,1]$}

ACAR

$\begin{array}{lll}0.450 & 0.437 & 0.476\end{array}$

ACSAR

$\begin{array}{lll}0.264 & 0.324 & 0.230\end{array}$

BMP t-statistic

$\begin{array}{lll}3.403 & 2.960 & 2.533\end{array}$

BMP p-val

$\begin{array}{lll}0.001 & 0.006 & 0.015\end{array}$

KP t-statistic

$\begin{array}{lll}2.298 & 2.280 & 1.820\end{array}$

KP p-val

$\begin{array}{lll}0.025 & 0.030 & 0.076\end{array}$

GRank Test

2.745

$2.605 \quad 2.248$

GRank p-val

$\begin{array}{lll}0.008 & 0.012 & 0.028\end{array}$

No. of Observations

60

31

41

\section{Panel B: Event Window $[1,2]$}

\begin{tabular}{lccc} 
ACAR & 0.310 & 0.789 & 0.347 \\
ACSAR & 0.375 & 0.540 & 0.275 \\
BMP t-statistic & 2.937 & 3.087 & 1.924 \\
BMP p-val & 0.005 & 0.004 & 0.061 \\
KP t-statistic & 1.983 & 2.378 & 1.383 \\
KP p-val & 0.052 & 0.024 & 0.174 \\
GRank Test & 2.105 & 2.354 & 1.619 \\
GRank p-val & 0.040 & 0.022 & 0.111 \\
No. of Observations & 60 & 31 & 41 \\
\hline
\end{tabular}

ACAR \& ACSAR are in \%. There is a 60 days estimation window from 2 April to 26 June 2009. The event window [1,1] captures the abnormal returns on 29 June 2009. The event window [1,2] adds 30 June 2009. The BMP test (Boehmer et al. 1991) is an extension of Patell (1976) and robust against event induced variance. The KP test (Kolary \& Pynnönen, 2010) is adjusting the BMP test for cross sectional correlation. The average correlations of abnormal returns $\bar{\rho}$ in our samples are $\bar{\rho}_{c l \& c c x}=$ $0.020, \bar{\rho}_{c c x}=0.022$, and $\bar{\rho}_{c l}=0.023$. The non-parametric GRank test is the generalized rank test for cumulated returns from Kolari and Pynnönen (2010a). 
tend the market model by adding to each security $i$ in business sector $\gamma$ the business sector return BUSret $\gamma$. In contrast to 10 economic sectors, we are now able to differentiate more subtly by controlling for 25 business sectors. The results for our third and strictest model specification, which is formally given by equation 4 are presented in Table 3 . The observable pattern reinforces the trend set by the previous specification with 10 economic sectors. In addition to the CL sample, the CCX sample now starts losing some of its verve: While there remains evidence of abnormal returns for the longer event window in panel B, controlling for business sectors in our third specification renders the statistical significance of abnormal returns in the short event window non-significant.

Let us take a closer look at the longer event window for the CCX sample in Table 3. The CARs are positively skewed, with a substantially higher mean than median value. This holds true for the standardized CARs as well. The previous specifications have shown consistently lower p-values for the BMP test in comparison to the KP test. This order has now switched. While the BMP test statistic implies a p-value above the $10 \%$ level, the stricter KP p-value retains statistical significance at this level. This switch can be explained by the average correlation of the abnormal returns $\bar{\rho}$, which has become slightly negative. The significance of the KP p-value is supported by the generalized rank test. This third specification suggests that business sector effects explain an additional part of the positive abnormal returns. Further indication that controlling for sectoral effects has increased the explanatory power is reflected by the changes in correlation of the abnormal returns $\bar{\rho}$ (see the notes in the according tables). This value decreases steadily with increasingly detailed model specification and tends to converge towards zero.

In sum, our results suggest that CCX firms have profited from the threat of regulation in addition to being overrepresented in favorable sectors. CL firms, on the other hand, were merely riding on the sectors' coattails.

\subsection{Event Returns: CCX membership announcement}

Our complementary event study investigates the market reaction to CCX membership announcements. We identify 26 firms declaring their engagement to the CCX, ranging from the founding members in 2003 up to the last announcements in 2008. These identified securities do not encompass ADRs, major listings, or illiquid securities. In a thorough search for confounding events two trading days before and after all 26 membership announcements we identify 6 firms for which other substantial information was becoming public during their announcement periods. This leaves us with a final sample of 20 firms.

Industry-specific effects are less of a concern in this setting. While the Waxman-Markey Bill has shown to have had a sudden and highly focused 
impact on entire industries at one point in time, mere membership announcements should hardly be confounded by such industry-wide effects. Moreover, our sample is scattered over several years. In contrast to the Waxman-Markey Bill, however, information leakage poses a potential problem. To address the possibility that insider information had affected the stock price before the firms' public statements, we extend the event window symmetrically around the announcement dates. In addition to calculating the cumulated abnormal returns over the short window $[0,1]$ we add two longer windows, $[-1,1]$ and $[-2,2]$, to allow for a direct comparison with Fisher-Vanden and Thorburn who used the same windows for CL membership announcements.

Table 4 presents the abnormal return estimates for the CCX membership announcements. Over the short window, both the ACAR and the ACSAR are slightly positive. This changes when expanding the event windows, with the longest window exhibiting negative returns across the board. However, none of the results are statistically significant. All test statistics are well above conventional significance levels and hence cannot reject the null hypothesis of normal returns upon the CCX membership announcements. This indicates that the market was indifferent to the firms' sudden voluntary engagement in the CCX.

This result qualifies the findings in Gans and Hintermann, where a positive market reaction was inferred for the same event. In sum, CCX firms seem to provoke a different market reaction upon membership announcement than CL firms do. Recall that in Fisher-Vanden and Thorburn's data, newly announced voluntary engagement in the CL initiative was vigorously punished with negative abnormal returns. 
Table 3: 4-Factor Business Sector Model

\begin{tabular}{|c|c|c|c|}
\hline & CL\&CCX & CCX & CL \\
\hline \multicolumn{4}{|c|}{ Panel A: Event Window $[1,1]$} \\
\hline ACAR & -0.196 & -0.260 & -0.063 \\
\hline ACSAR & 0.029 & 0.082 & 0.021 \\
\hline BMP t-statistic & 0.345 & 0.694 & 0.213 \\
\hline BMP p-val & 0.731 & 0.493 & 0.832 \\
\hline KP t-statistic & 0.345 & 0.712 & 0.199 \\
\hline KP p-val & 0.731 & 0.482 & 0.844 \\
\hline GRank Test & 0.516 & 0.644 & 0.577 \\
\hline GRank p-val & 0.608 & 0.522 & 0.566 \\
\hline No. of Observations & 60 & 31 & 41 \\
\hline \multicolumn{4}{|c|}{ Panel B: Event Window $[1,2]$} \\
\hline ACAR & 0.259 & 0.684 & 0.270 \\
\hline ACSAR & 0.127 & 0.303 & 0.074 \\
\hline BMP t-statistic & 0.962 & 1.679 & 0.507 \\
\hline BMP p-val & 0.340 & 0.103 & 0.615 \\
\hline KP t-statistic & 0.964 & 1.722 & 0.472 \\
\hline KP p-val & 0.339 & 0.095 & 0.639 \\
\hline GRank Test & 1.005 & 1.674 & 0.815 \\
\hline GRank p-val & 0.319 & 0.100 & 0.419 \\
\hline No. of Observations & 60 & 31 & 41 \\
\hline
\end{tabular}

ACAR \& ACSAR are in \%. There is a 60 days estimation window from 2 April to 26 June 2009. The event window [1,1] captures the abnormal returns on 29 June 2009. The event window [1,2] adds 30 June 2009. The BMP test (Boehmer et al. 1991) is an extension of Patell (1976) and robust against event induced variance. The KP test (Kolary \& Pynnönen, 2010) is adjusting the BMP test for cross sectional correlation. The average correlations of abnormal returns $\bar{\rho}$ in our samples are $\bar{\rho}_{c l \& c c x}=$ $0.000, \bar{\rho}_{c c x}=-0.002$, and $\bar{\rho}_{c l}=0.004$. The non-parametric GRank test is the generalized rank test for cumulated returns from Kolari and Pynnönen (2010a). 
Table 4: Three event windows based on the 3-factor model

\begin{tabular}{lccc}
\hline & {$[\mathbf{0 , 1}]$} & {$[\mathbf{- 1 , 1}]$} & {$[\mathbf{- 2 , 2}]$} \\
\hline ACAR & 0.150 & -0.213 & -0.513 \\
ACSAR & 0.185 & 0.168 & -0.024 \\
& & & \\
Patell t-statistic & 0.813 & 0.738 & -0.107 \\
Patell p-val & 0.420 & 0.464 & 0.915 \\
& & & \\
BMP t-statistic & 0.517 & 0.319 & -0.043 \\
BMP p-val & 0.607 & 0.751 & 0.966 \\
& & & \\
KP t-statistic & 0.455 & 0.281 & -0.038 \\
KP p-val & 0.651 & 0.780 & 0.970 \\
& & & \\
GRank Test & 0.897 & 0.454 & 0.011 \\
GRank p-val & 0.374 & 0.651 & 0.991
\end{tabular}

\begin{tabular}{l} 
Nr. of Observations $20 \quad 20$ \\
\hline ACAR \& ACSAR in \%. There is a 60 days estimation window from 2 April \\
to 26 June 2009. The BMP test (Boehmer et al. 1991) is an extension of \\
Patell (1976) and robust against event induced variance. The KP test (Kolary \\
$\&$ Pynnönen, 2010) is adjusting the BMP test for cross sectional correlation. \\
The average correlation of abnormal returns $\bar{\rho}$ in our sample is $\bar{\rho}=0.015$. The \\
non-parametric GRank test is the generalized rank test for cumulated returns \\
from Kolari and Pynnönen (2010a).
\end{tabular}




\section{Conclusion}

Conclusive evidence for the motivation to join voluntary environmental initiatives is instructive for the ongoing discourse about the economic value of these initiatives. It informs future policy designers of the effects of mandatory regulation and lets investors know whether voluntary initiatives are beneficial. This paper compares the perceived market value of two voluntary climate initiatives by exploiting two decisive and unexpected events. In our principal event study we compare the immediate effect of the WaxmanMarkey Bill on stock prices for members of the Climate Leaders (CL) and the Chicago Climate Exchange (CCX), two initiatives who pursued the goal of curbing $\mathrm{CO}_{2}$ emissions with different strategies. The Waxman-Markey Bill intended to establish a mandated carbon market in the US and surprisingly passed the vote in the House of Representatives in June 2009, temporarily inducing a credible economic threat in the form of unforeseen adjustment costs in the short run. The close passing of the bill lends itself particularly well to an event study. To round up the picture, in a complementary event study we compare the market reaction to the preceding membership announcements to these two initiatives.

On the surface, the market reaction to the Waxman-Markey Bill indicates a positive value correction for both CL and CCX firms, suggesting that the market considered membership in these initiatives an advantageous headstart for the seemingly upcoming mandated carbon market. It stands to reason, however, that the implementation of the Waxman-Markey Bill would likely have affected entire industries. In a more detailed specification, we isolate the firm level effect by extending the baseline model specification with economic and, on a deeper level, business sector returns. This puts the positive market reaction towards the CL and the CCX firms into perspective. Members of the CCX continue to show positive abnormal returns, albeit at decidedly lower levels. For the CL firms the industry effects fully account for the observed positive returns during the passage of the bill.

In our complementary event study, we investigate and compare the earlier market reactions towards membership announcements to these initiatives. In their event study, Fisher-Vanden and Thorburn (2011) found significant negative effects when firms announced their CL engagement. How do new CCX members fare in direct comparison? Our results cannot reject a neutral market reaction for CCX membership announcements, contradicting previous findings. In contrast to the negative CL effects, our results indicate that the market had not believed that, on the whole, CCX engagement would be a detrimental venture. Obviously, both initiatives entailed considerable costs for the firms in the short run. The reactions to the membership announcements would then suggest that the advantages of membership outweighed these costs for the CCX engagement but not for the CL initiative. In other words, there only seemed good reason to join the CCX, not the CL. 
Taken together, the market reactions in light of the two events paint a coherent picture of the perceived value of membership in the two initiatives. CCX membership announcements per se did not provoke a market reaction, but membership was deemed beneficial in riskier times. The significant abnormal returns for the CCX members during the passage of the bill are likely to be explained by the fact that this program had already effectively mirrored the workings of a regulatory cap-and-trade system as intended by the bill. Third party verification of the environmental effort of the CCX members only added to the credibility of their commitment. In contrast, the CL initiative had been penalized upon participation, and membership was not considered an advantage when the going got tough with the WaxmanMarkey Bill. These market reactions set the CCX apart from the CL, who followed a less streamlined path for $\mathrm{CO}_{2}$ emission reduction. The CL members acquired firm internal knowledge on how to implement an emission management system and how to identify and pursue reduction opportunities in general. But the CL members could not gain trading experience and knowledge from participation in an active carbon market. Moreover, they relied on self-auditing, raising serious doubts about their credibility.

We caution against generalizing our results. Membership in these initiatives was voluntary and therefore endogenous. It therefore seems plausible that the observed market reaction for members would establish an upper bound when thinking about enforcing mandatory membership for other firms. On the other hand, one might argue that the Waxman-Markey event came about by a publicly known voting process. Heated discussions preceded the passage of the bill, so the event cannot be considered fully dichotomous. This would underestimate the entire effect of mandatory regulation, for completely unexpected and full inversions would trigger more pronounced market reactions.

Our results corroborate the hypothesis that, given a proper design, the market can consider membership in fitting voluntary environmental programs a worthwhile venture if future regulation is foreshadowing. Effective preparation seems to be key. Existing empirical evidence has shown that membership in voluntary environmental initiatives has mixed effects on stock prices. Such effects could be attributable to diverging beliefs of investors and firms about the benefit of membership. Our results shed light on the question which kind of initiatives, if any, the market considers more expedient in terms of preparation. 


\section{References}

Betzer, A., M. Doumet, and U. Rinne (2013, May). How policy changes affect shareholder wealth: the case of the Fukushima Dai-ichi nuclear disaster. Applied Economics Letters 20(8), 799-803.

Blacconiere, W. G. and W. D. Northcut (1997, April). Environmental Information and Market Reactions to Environmental Legislation. Journal of Accounting, Auditing \& Finance 12(2), 149-178.

Blacconiere, W. G. and D. M. Patten (1994, November). Environmental disclosures, regulatory costs, and changes in firm value. Journal of Accounting and Economics 18(3), 357-377.

Blanco, E., J. Rey-Maquieira, and J. Lozano (2009, July). The Economic Impacts of Voluntary Environmental Performance of Firms: a Critical Review. Journal of Economic Surveys 23(3), 462-502.

Boehmer, E., J. Musumeci, and Annette B. Poulsen (1991). Event-study methodology under conditions of event-induced variance. Journal of Financial Economics 30, 253-72.

Bowen, R. M., R. P. Castanias, and L. A. Daley (1983, March). IntraIndustry Effects of the Accident at Three Mile Island. The Journal of Financial and Quantitative Analysis 18(1), 87.

Brown, S. J. and J. B. Warner (1980). Measuring security price performance. Journal of Financial Economics 8, 205-258.

Bushnell, B. J. B., H. Chong, and E. T. Mansur (2013). Profiting from Regulation: Evidence from the European Carbon Market. American Economic Journal: Economic Policy 5(4), 78-106.

Cropper, M. L. and W. E. Oates (1992). Environmental Economics: A Survey. Journal of Economic Literature 30(2), 675-740.

Fama, E. F. and K. R. French (1992, June). The Cross-Section of Expected Stock Returns. The Journal of Finance 47(2), 427.

Fama, E. F. and K. R. French (1993). Common risk factors in the returns on stocks and bonds. Journal of Financial Economics 33(1), 3-56.

Financial Times (2010, November). End of US carbon trading looms.

Fisher-Vanden, K. and K. S. Thorburn (2011, April). Voluntary corporate environmental initiatives and shareholder wealth. Journal of Environmental Economics and Management 62 (3), 430-445. 
Fleckinger, P. and M. Glachant (2011, July). Negotiating a voluntary agreement when firms self-regulate. Journal of Environmental Economics and Management 62(1), 41-52.

Freedman, M. and D. M. Patten (2004, March). Evidence on the pernicious effect of financial report environmental disclosure. Accounting Forum 28(1), 27-41.

Gans, W. and B. Hintermann (2013, January). Market Effects of Voluntary Climate Action by Firms: Evidence from the Chicago Climate Exchange. Environmental and Resource Economics 55(2), 291-308.

Harrington, S. E. and D. G. Shrider (2013). All Events Induce Variance : Analyzing Abnormal Returns When Effects Vary across Firms Firms. Journal of Financial and Quantitative Analysis 42(1), 229-256.

Hill, J. and T. Schneeweis (1983, September). The Effect of Three Mile Island on Electric Utility Stock Prices: A Note. The Journal of Finance 38(4), 1285-1292.

Kahn, S. and C. R. . Knittel (2003). The Impact of the Clean Air Act Amendments of 1990 on Electric Utilities and Coal Mines : Evidence from the Stock Market.

Khanna, M. (2002, December). Non-Mandatory Approaches to Environmental Protection. Journal of Economic Surveys 15(3), 291-324.

Kim, E.-H. and T. P. Lyon (2011). When Does Institutional Investor Activism Increase Shareholder Value?: The Carbon Disclosure Project. The B.E. Journal of Economic Analysis \& Policy 11(1), Article 50.

Kolari, J. W., J. P. Morgan, and A. Texas (2010). Nonparametric Rank Tests for Event Studies.

Kolari, J. W. and S. Pynnonen (2010, September). Event Study Testing with Cross-sectional Correlation of Abnormal Returns. Review of Financial Studies 23(11), 3996-4025.

Kothari, S. P. and J. B. Warner (2007). Econometrics of event studies. In B. E. Eckbo (Ed.), Handbook of Empirical Corporate Finance (1 ed.)., Chapter 1, pp. 3-36. North Holland.

Lyon, T. P. and J. W. Maxwell (2003, August). Self-regulation, taxation and public voluntary environmental agreements. Journal of Public Economics 87(7-8), 1453-1486.

Lyon, T. P. and J. W. Maxwell (2008, July). Corporate Social Responsibility and the Environment: A Theoretical Perspective. Review of Environmental Economics and Policy 2(2), 240-260. 
MacKinlay, A. C. (1997). Event Studies in Economics and Finance. Journal of Economic Literature 35(1), 13-39.

McWilliams, A. and D. Siegel (1997). Event Studies in Management Research: Theoretical and Empirical Issues. The Academy of Management Journal 40(3), 626-657.

Meng, K. (2013). The Cost of Potential Cap-and-Trade Policy: An Event Study using Prediction Markets and Lobbying Records.

National Geographic News (2010, November). A U.S. Cap-and-Trade Experiment To End.

Oberndorfer, U., P. Schmidt, M. Wagner, and A. Ziegler (2013, May). Does the stock market value the inclusion in a sustainability stock index? An event study analysis for German firms. Journal of Environmental Economics and Management 66(3), 497-509.

Patell, J. M. (1976). Corporate Forecasts of Earnings per Share and Stock Price Behavior : Empirical Tests. Journal of Accounting Research 14(2), 246-276.

Portney, P. R. (2008, July). The (Not So) New Corporate Social Responsibility: An Empirical Perspective. Review of Environmental Economics and Policy 2(2), 261-275.

Telle, K. (2013). Monitoring and enforcement of environmental regulations. Lessons from a natural field experiment in Norway. Journal of Public Economics 99, 24-34.

Tonkonogy, B. and M. J. Oliva (2007). Introduction to the Climate Leaders Program : Introduction for New Partners. Climate Leaders partners Meeting, December 3, 2007. Number December. 


\section{Tables}

Table A1: Climate Leader Membership Development

\begin{tabular}{lcccc}
\hline Date & \# Firms & Achievers & Setters & Developers \\
\hline $\mathbf{2 8 . 0 3 . 2 0 0 8}$ & 162 & 11 & 69 & 82 \\
$\mathbf{2 1 . 0 5 . 2 0 0 8}$ & 172 & 11 & 69 & 92 \\
$\mathbf{0 3 . 0 1 . 2 0 0 9}$ & 249 & 18 & 85 & 146 \\
$\mathbf{0 8 . 0 5 . 2 0 0 9}$ & 264 & 19 & 87 & 158 \\
$\mathbf{0 1 . 0 8 . 2 0 1 0} *$ & 191 & 26 & 93 & 72 \\
$\mathbf{1 3 . 0 2 . 2 0 1 1}$ & 183 & 32 & 100 & 51 \\
\hline
\end{tabular}

* Retrieved on September 202012 from:

http://www.epa.gov/climateleadership/documents/directory.pdf

All other dates are from lists retrieved from www.archive.org

Table A2: No. of Firms in Samples

\begin{tabular}{lccccc}
\hline & \multicolumn{3}{c}{ Waxman-Markey Event } & & Membership Announcements \\
\cline { 2 - 3 } & CL\&CCX & CCX & CL & & CCX \\
\hline Identified* & 84 & 40 & 57 & & 26 \\
Confounding events & 24 & 9 & 16 & & 6 \\
Resulting sample & 60 & 31 & 41 & & 20 \\
\hline * Identified firms without illiquid firms or ADRs. & & &
\end{tabular}


Table A3: Chicago Climate Exchange Firms (CCX) and Event Samples

\begin{tabular}{|c|c|c|c|}
\hline Firm name & Sample & mbership* & Charter member \\
\hline Abbott Laboratories & MA & & \\
\hline Agrium U.S. Inc. & & W\&M & \\
\hline Alliant Energy Corporate Services Inc. & & W\&M & \\
\hline American Electric Power & MA & W\&M & charter member \\
\hline Avista Corporation & MA & W\&M & \\
\hline Bank of America Corporation & & W\&M & \\
\hline Baxter International Inc. & MA & $\mathrm{W} \& \mathrm{M}$ & charter member \\
\hline Boise Paper Holdings, LLC & MA & W\&M & \\
\hline CLECO Corporation & & $\mathrm{W} \& \mathrm{M}$ & \\
\hline Central Vermont Public Service & MA & W\&M & \\
\hline Dow Corning & & W\&M & \\
\hline DTE Energy Inc & MA & W\&M & \\
\hline DuPont & & W\&M & charter member \\
\hline Eastman Kodak Company & & W\&M & \\
\hline FMC Corporation & & W\&M & \\
\hline Ford Motor Company & & $\mathrm{W} \& \mathrm{M}$ & charter member \\
\hline Genon Energy Inco. & MA & & \\
\hline Green Mnt.Power Corp. & MA & & \\
\hline Intel Corporation & MA & W\&M & \\
\hline Interface, Inc. & MA & $\mathrm{W} \& \mathrm{M}$ & \\
\hline IBM & MA & W\&M & \\
\hline International Paper & & W\&M & charter member \\
\hline Knoll, Inc. & MA & $\mathrm{W} \& \mathrm{M}$ & \\
\hline MeadWestvaco Corp. & MA & W\&M & charter member \\
\hline Mirant Corporation & & W\&M & \\
\hline Motorola, Inc. & & W\&M & charter member \\
\hline Neenah Paper Incorporated & MA & W\&M & \\
\hline Nrg Energy Inco. & MA & & \\
\hline Plum Creek Timber Company, Inc. & & $\mathrm{W} \& \mathrm{M}$ & \\
\hline PSEG Energy Resources \& Trade LLC & & $\mathrm{W} \& \mathrm{M}$ & \\
\hline Puget Energy Inco. & MA & & \\
\hline Safeway Incorporated & MA & & \\
\hline Steelcase Inc. & & $\mathrm{W} \& \mathrm{M}$ & \\
\hline TECO Energy, Inc. & & W\&M & \\
\hline Temple-Inland Inc & MA & W\&M & charter member \\
\hline United Technologies Corporation & & $\mathrm{W} \& \mathrm{M}$ & \\
\hline Waste Management, Inc. & MA & $\mathrm{W} \& \mathrm{M}$ & charter member \\
\hline
\end{tabular}

\footnotetext{
Sample membership*: - W\&M; Waxman-Markey event sample

- MA; Membership Announcement sam-

ple.
} 
Table A4: Sample of Climate Leader Firms (CL) for Waxman-Markey Event

\begin{tabular}{|c|c|c|c|}
\hline Firm name & CL status* & Charter partner & Reduction region \\
\hline $3 \mathrm{M}$ & achievers & & U.S. GHG \\
\hline Advanced Micro Devices, Inc. & achievers & charter partner & global GHG \\
\hline Agilent Technologies & setters & & global GHG \\
\hline American Electric Power & achievers & & U.S. GHG \\
\hline Applied Materials, Inc. & setters & & global GHG \\
\hline Bank of America Corporation & setters & & U.S. GHG \\
\hline Baxter International Inc. & achievers & charter partner & U.S. GHG \\
\hline Best Buy Co., Inc. & setters & & U.S. GHG \\
\hline Calpine & setters & & U.S. GHG \\
\hline Campbell Soup Company & setters & & U.S. GHG \\
\hline Caterpillar Inc. & achievers & & global GHG \\
\hline Cisco Systems, Inc. & setters & & global GHG \\
\hline Cummins Inc. & setters & & global GHG \\
\hline Dell Inc. & setters & & global GHG \\
\hline DuPont Company & setters & & global GHG \\
\hline Eastman Kodak Company & setters & charter partner & global GHG \\
\hline Ecolab, Inc. & setters & & U.S. GHG \\
\hline EMC Corporation & setters & & U.S. GHG \\
\hline Fairchild Semiconductor & setters & & U.S. GHG \\
\hline Hasbro, Inc. & achievers & charter partner & U.S. GHG \\
\hline Intel Corporation & setters & & global GHG \\
\hline Interface, Inc. & setters & charter partner & U.S. GHG \\
\hline IBM Corporation & achievers & charter partner & global GHG \\
\hline International Paper & setters & charter partner & U.S. GHG \\
\hline Johnson Controls, Inc. & setters & & U.S. GHG \\
\hline LSI Corporation & setters & & U.S. GHG \\
\hline Marriott International, Inc. & setters & & U.S. GHG \\
\hline Merck \& Co., Inc. & setters & & global GHG \\
\hline Millipore Corporation & setters & & global GHG \\
\hline Coors Brewing Company & setters & & U.S. GHG \\
\hline FPL Group, Inc. & achievers & charter partner & U.S. GHG \\
\hline NVIDIA Corporation & setters & & U.S. GHG \\
\hline Owens Corning & setters & & U.S. GHG \\
\hline PepsiCo & setters & & U.S. GHG \\
\hline PPG Industries, Inc. & setters & & global GHG \\
\hline PSEG & setters & charter partner & U.S. GHG \\
\hline Staples, Inc. & setters & charter partner & U.S. GHG \\
\hline Steelcase Inc. & setters & & U.S. GHG \\
\hline Gap, Inc. & setters & & U.S. GHG \\
\hline United Technologies Corporation & achievers & & global GHG \\
\hline Xerox Corporation & achievers & & global GHG \\
\hline
\end{tabular}

CL status*: Status of Climate Leader member with regard

to emission reduction pledge. 
Table A5: 4-Factor Economic Sector Model

CL\&CCX CCX CL

\begin{tabular}{lccc}
\hline Panel A: event window $[\mathbf{1 , 1}]$ & & & \\
ACAR & -0.047 & 0.102 & -0.082 \\
ACSAR & 0.073 & 0.204 & 0.011 \\
BMP t-statistic & 0.896 & 1.829 & 0.118 \\
BMP p-val & 0.374 & 0.077 & 0.907 \\
KP t-statistic & 0.808 & 1.796 & 0.100 \\
KP p-val & 0.422 & 0.082 & 0.920 \\
GRank Test & 1.173 & 1.903 & 0.513 \\
GRank p-val & 0.245 & 0.062 & 0.610 \\
Nr. of Observations & 60 & 31 & 41 \\
\hline Panel B: event window[1,2] & & & \\
ACAR & 0.276 & 0.717 & 0.294 \\
ACSAR & 0.185 & 0.436 & 0.063 \\
BMP t-statistic & 1.423 & 2.479 & 0.432 \\
BMP p-val & 0.160 & 0.019 & 0.668 \\
KP t-statistic & 1.283 & 2.435 & 0.367 \\
KP p-val & 0.204 & 0.021 & 0.715 \\
GRank Test & 1.442 & 2.247 & 0.664 \\
GRank p-val & 0.155 & 0.028 & 0.509 \\
Nr. of Observations & 60 & 31 & 41 \\
\hline ACAR \& ACSAR are $\%$ Then & & & \\
\hline
\end{tabular}

ACAR \& ACSAR are in \%. There is a 60 days estimation window from 2 April to 26 June 2009. The event window [1,1] captures the abnormal returns on 29 June 2009. The event window [1,2] adds 30 June 2009. The BMP test (Boehmer et al. 1991) is an extension of Patell (1976) and robust against event induced variance. The KP test (Kolary \& Pynnönen, 2010) is adjusting the BMP test for cross sectional correlation. The average correlations of abnormal returns $\bar{\rho}$ in our samples are $\bar{\rho}_{c l \& c c x}$ $=0.004, \bar{\rho}_{c c x}=0.001$, and $\bar{\rho}_{c l}=0.009$. The non-parametric GRank test is the generalized rank test for cumulated returns from Kolari and Pynnönen (2010a). 